\title{
Characterization of Geminivirus Resistance in an Accession of Capsicum chinense Jacq.
}

\author{
Marco A. García-Neria and Rafael F. Rivera-Bustamante \\ Departamento de Ingeniería Genética, Cinvestav Unidad Irapuato, Km 9.6 Libramiento Norte, Carretera Irapuato-León, 36821, \\ Irapuato, Gto, Mexico
}

Submitted 3 June 2010. Accepted 24 September 2010.

Pepper golden mosaic virus (PepGMV) and Pepper huasteco yellow vein virus (PHYVV), members of the Geminiviridae family, are important pathogens of pepper (Capsicum annuum L.) and other solanaceous crops. Accession BG-3821 of $C$. chinense Jacq. was reported earlier as resistant to mixed infection with PepGMV and PHYVV. In this work, we characterized the Geminivirus resistance trait present in BG-3821. Segregation analysis suggested that resistance depends on two genes. Our data showed that PepGMV replication in protoplast of resistant plants is approximately 70\% lower when compared with the levels observed in protoplasts from susceptible plants. Additionally, viral movement is less efficient in resistant plants. We also evaluated several characteristics commonly associated with systemic acquired resistance (SAR), which is a conserved defensive mechanism. The concentration of salicylic acid was higher in resistant plants inoculated with PepGMV than in susceptible plants. Marker genes for SAR were induced after inoculation with PepGMV in resistant leaves. Similarly, we found a higher accumulation of reactive oxygen species on resistant leaves compared with susceptible ones. A model for the mechanism acting in the Geminivirus resistance detected in BG-3821 is proposed. Finally, the importance of BG-3821 in Geminivirus resistance breeding programs is discussed.

Geminivirus spp. are a large family of plant viruses with a circular, single-stranded DNA genome that infect a wide variety of crops worldwide, causing serious reductions in productivity. The family Geminiviridae is divided into four genera according to their genome organization, insect vector, and host range. Species of genus Begomovirus are transmitted by whiteflies (Bemisia tabaci Genn.), are widespread, and cause the most devastating geminiviral diseases (Moffat 1999; Morales and Anderson 2001; Varma and Malathi 2003). In Mexico, diseases caused by Begomovirus spp. such as Pepper golden mosaic virus (PepGMV) and Pepper huasteco yellow vein virus (PHYVV) have emerged as an important problem in pepper (Capsicum annuum L.) and other economically important crops such as tomato, tomatillo, and tobacco (Holguín-Peña et al. 2007; Torres-Pacheco et al. 1996).

Today, control of diseases caused by Begomovirus spp. is mainly based on the management of the vector. Strategies

Corresponding author: Rafael F. Rivera-Bustamante;

E-mail: rrivera@ira.cinvestav.mx

* The $\boldsymbol{e}$-Xtra logo stands for "electronic extra" and indicates that four supplementary figures are published online and that Figures 5 and 7 appear in color online. implemented to avoid virus transmission by whitefly include planting during whitefly-free periods and protecting crops using row covers, with insecticide applications being the last strategy and perhaps the most widely used (Holguín-Peña et al. 2007; Ji et al. 2007; Lapidot and Friedmann 2002). However, these strategies, in addition to increasing costs, are insufficient to prevent disease spread. Therefore, generation of resistant cultivars by genetic engineering and traditional breeding has become a priority (Lapidot and Friedmann 2002; Moffat 1999). Different strategies for transgenic resistance have been evaluated since the emergence of Geminivirus spp. as a major problem. However, to date, most of the transgenic plants have provided only moderate levels of resistance (Shepherd et al. 2009; Vanderschuren et al. 2007). Conventional breeding as an alternative strategy to transgenesis is based on the identification of resistance sources in wild relatives and their use in breeding programs. Significant advances have been done in tomato to produce cultivars resistant to Tomato yellow leaf curl virus (TYLCV) using introgression from wild relatives. Also, extensive screenings to discover Geminivirus resistance sources have been done in common bean, cassava, and cotton ( $\mathrm{Ji}$ et al. 2007; Lapidot and Friedmann 2002). In pepper, there are no commercial cultivars with Geminivirus resistance or tolerance currently available; therefore, several screenings have been done to discover Geminivirus spp.-resistant plants (AnayaLópez et al. 2003; Godínez-Hernández et al. 2001; HernándezVerdugo et al. 2001). Recently, the accession BG-3821 of $C$. chinense Jacq. was identified as resistant to PepGMV and PHYVV (Anaya-López et al. 2003).

In this work, the resistance to PepGMV in accession BG3821 was further characterized. In order to evaluate the genetic complexity of the resistance trait, an analysis of segregation was carried out. Susceptible and resistant plants identified in the segregation analysis were used in further experiments. Because replication and movement are two important processes for viral infection (Rojas et al. 2005), both processes were also evaluated. Viral replication was evaluated by quantitative polymerase chain reaction (PCR) in protoplasts isolated from both resistant and susceptible plants. Viral movement was evaluated on inoculated and systemically infected leaves using several methodologies, including PepGMV-GFP fusions, tissue printing, and grafting experiments.

Finally, we were also interested in studying which defensive mechanism could be involved in PepGMV resistance. Systemic acquired resistance (SAR) is one the most conserved mechanisms of resistance to several pathogens, including viruses (Chivasa et al. 1997; Durrant and Dong 2004; Kachroo et al. 2000; Vlot et al. 2009). Therefore, we decided to evaluate $\mathrm{H}_{2} \mathrm{O}_{2}$ and salicylic acid (SA) accumulation and the induction of pathogenesis-related (PR) genes as hallmarks for SAR. Based 
on the results, we propose that PepGMV resistance in BG-3821 depends on the early response to pathogen attack and an opportune SAR induction.

\section{RESULTS}

Resistance trait depends on two genes.

Currently, there are no commercial pepper cultivars resistant to Geminivirus spp. Some efforts to find resistance genes in wild relatives have been carried out recently (Anaya-López et al. 2003; Godinez-Hernández et al. 2001; Hernández-Verdugo et al. 2001). Accession BG-3821 was first identified as resistant to PepGMV and PHYVV, two important and common Geminivirus spp. in Mexico (Anaya-López et al. 2003). In the work presented here, resistance evaluation was done by biolistic inoculation with PepGMV of the progeny of self-pollinated (S1) plants. Results showed that S1 progeny segregate in two phenotypes: i) resistant plants (henceforth called BG-3821-R), which remained asymptomatic after biolistic inoculation, and ii) susceptible plants (BG-3821-S), which showed typical PepGMV symptoms 9 to 12 days postinoculation (dpi) (Fig. 1). Segregation of the progeny into susceptible and resistant plants indicated that the original field-selected plant was heterozygous for the Geminivirus resistance characteristic. Summary of data obtained in four batches presented a good fit for a 9:7 (resistant/susceptible) ratio, which suggested a duplicate recessive epistatic relation between two genes (Table 1).

In our scheme, the characterization of an individual plant as resistant or susceptible requires its inoculation with PepGMV. As previously reported, resistant plants, although asymptomatic, contain a reduced amount of virus. Because our goal was to obtain virus-free resistant and susceptible plants for further experiments, the subsequent segregation analyses were carried out using a grafting strategy (Supplementary Fig. S1). Scions of S1 plants were grafted onto C. annuum cv. Sonora Anaheim previously characterized as highly susceptible to Geminivirus infection (Carrillo-Tripp et al. 2007; Méndez-Lozano et al. 2003). Then, for resistance evaluation, scions of the grafted plants were inoculated with PepGMV using a biolistic procedure. With this strategy, we were able to analyze individual S1 progeny plants while keeping a noninoculated "copy" of each plant. As a control, at least 10 susceptible pepper plants (cv. Sonora Anaheim) were included in each batch. Under our experimental conditions, $100 \%$ of control plants developed typical PepGMV symptoms.

\section{Evaluation of PepGMV accumulation in systemically infected leaves.}

Previously, it was reported that infected resistant plants BG3821 , although symptomless, were able to accumulate a low concentration of viral DNA (Anaya-López et al. 2003). We evaluated the accumulation of PepGMV in systemically infected tissue from resistant and susceptible plants using quantitative PCR. Evaluations were carried out at several times after inoculation. At $2 \mathrm{dpi}$, both resistant and susceptible plants showed a low concentration of PepGMV DNA. At 5 dpi, there was already a difference in the concentration of viral DNA detected in resistant and susceptible plants. This difference was still more evident at $10 \mathrm{dpi}$, when it correlated with the appearance of symptoms in the susceptible plants (Fig. 2). To verify which process of the virus cycle was affected on the resistant plants, an additional series of experiments was carried out.

Table 1. Segregation analysis of Pepper golden mosaic virus resistance in BG3821

\begin{tabular}{llccc}
\hline & & \multicolumn{2}{c}{ S1 progeny } & \\
\cline { 3 - 4 } Batch & Phenotype & Observed & Expected & $\chi^{\mathbf{2}} \mathbf{( 9 : 7 ) ^ { \mathbf { a } }}$ \\
\hline $\mathrm{I}^{\mathrm{b}}$ & Resistant & 15 & 14.0625 & 0.14 \\
& Susceptible & 10 & 10.9375 & \\
$\mathrm{II}^{\mathrm{c}}$ & Resistant & 33 & 35.4375 & 0.38 \\
& Susceptible & 30 & 27.5625 & \\
$\mathrm{III}^{\mathrm{c}}$ & Resistant & 28 & 28.6875 & 0.04 \\
& Susceptible & 23 & 22.3125 & \\
$\mathrm{IV}^{\mathrm{c}}$ & Resistant & 80 & 82.6875 & 0.2 \\
& Susceptible & 67 & 64.3125 & \\
Total & Resistant & 156 & 160.875 & 0.34 \\
& Susceptible & 130 & 125.125 & $\ldots$ \\
\hline
\end{tabular}

${ }^{a} P<0.05$ in every batch and in the total.

b $\mathrm{S} 1$ plants were evaluated by direct inoculation.

c S1 plants were grafted onto susceptible Sonora Anaheim plants. At least 10 Sonora Anaheim plants were inoculated in each batch as a control for inoculation efficiency.
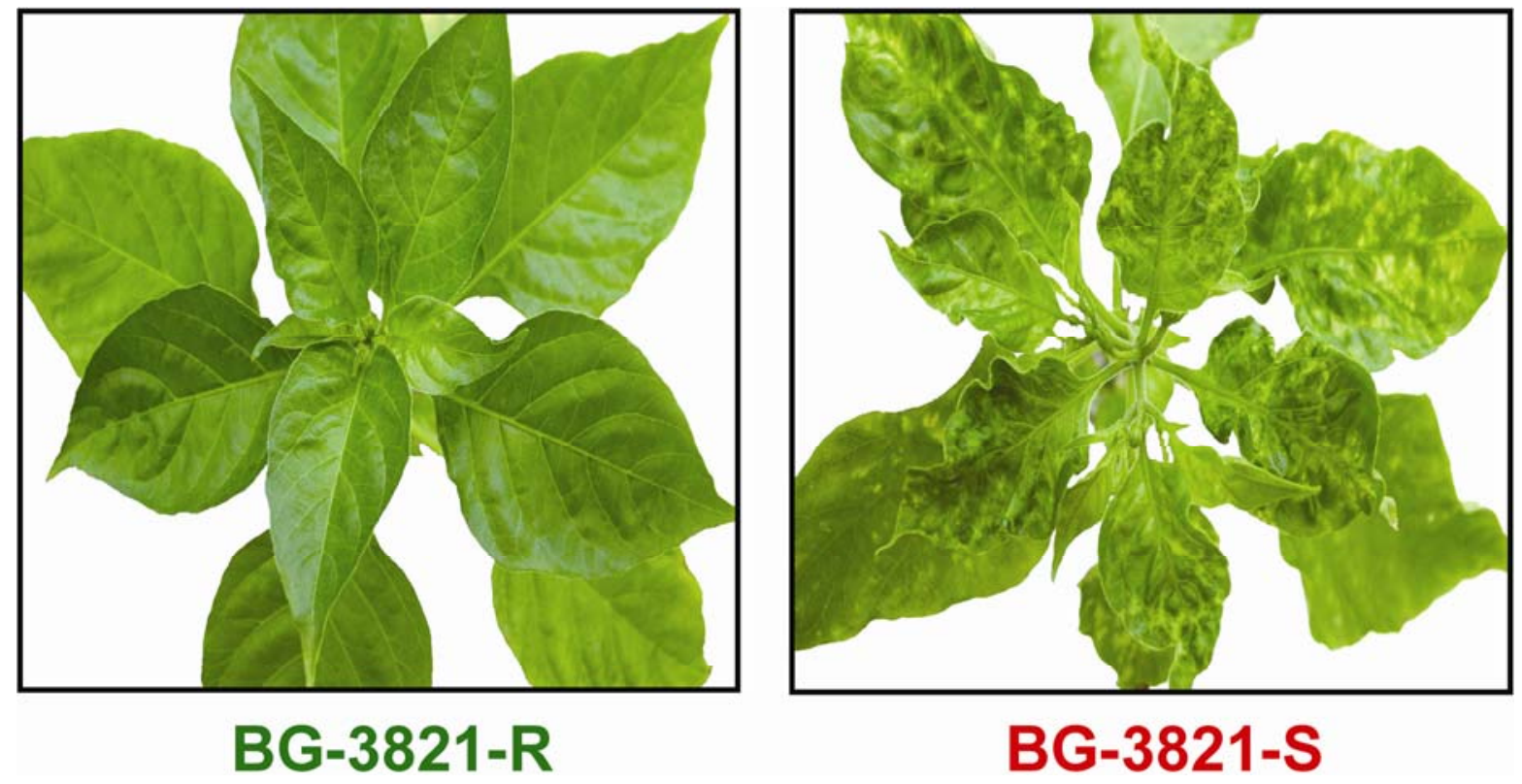

Fig. 1. Resistance segregation analysis. S1 plants were inoculated with Pepper golden mosaic virus. Pictures were taken 16 days postinoculation (dpi). Phenotype of resistant (BG-3821-R) and susceptible (BG-3821-S) plants. 
Viral replication is less efficient in resistant plants.

Viral replication rate is an important parameter evaluated in genotypes selected as resistant. Several techniques have been used to evaluate replication. Those include agroinoculation of leaf discs (Czosnek et al. 1993; Day et al. 1991) and evaluation in protoplasts from candidate plants (Brunetti et al. 2001; Lucioli et al. 2003) or from cell suspension cultures (LopezOchoa et al. 2006; Méndez-Lozano et al. 2003). In this study, viral replication was evaluated in intact plants as well as protoplasts from leaves of resistant and susceptible plants. The assays with intact plants were carried out by inoculating resistant and susceptible plants using a handheld biolistic gun that allows a direct inoculation to a single leaf (Carrillo-Tripp et al. 2007). Inoculated leaves were then collected $48 \mathrm{~h}$ postinoculation (hpi) and viral replication was analyzed essentially as described below in the protoplast experiment. Viral replication on resistant plants was reduced compared with the levels observed in susceptible plants. However, the inoculation included both components (PepGMV A and B); therefore, a possible effect due to differential virus movement in the resistant plants cannot be excluded. For that reason, some experiments with protoplast were also performed. This strategy allowed us to eliminate the influence of cell-to-cell and long-distance viral movement. Protoplasts obtained from BG-3821-R and BG-3821-S plants were transfected with PepGMV-A and incubated for $48 \mathrm{~h}$; then, viral DNA quantification was performed using quantitative PCR as previously reported (Carrillo-Tripp et al. 2007). Transfection efficiency was evaluated using 35S:GFP (green fluorescent protein) as a reporter. To avoid interference of initially inoculated PepGMV, a DpnI treatment was done as reported (Lopez-Ochoa et al. 2006). Under our conditions, no PepGMV amplification was detected at $0 \mathrm{~h}$ posttransfection (hpt) in control, transfected protoplasts that were treated with DpnI. Results from two independent experiments showed that viral replication in protoplasts from resistant plants is approximately $70 \%$ less efficient compared with the replication observed in susceptible plants (100\%) (Fig. 3).

\section{Viral movement is less efficient in resistant plants.}

Another important process in viral cycle is movement (Rojas et al. 2005). In this work, viral movement was evaluated using different strategies. Preliminary results with leaf detachment experiments showed that $48 \mathrm{~h}$ was sufficient for PepGMV to move out from the inoculated leaf and induce symptoms (Supplementary Fig. S2). Virus movement was evaluated in both resistant and susceptible BG-3821 plants 48

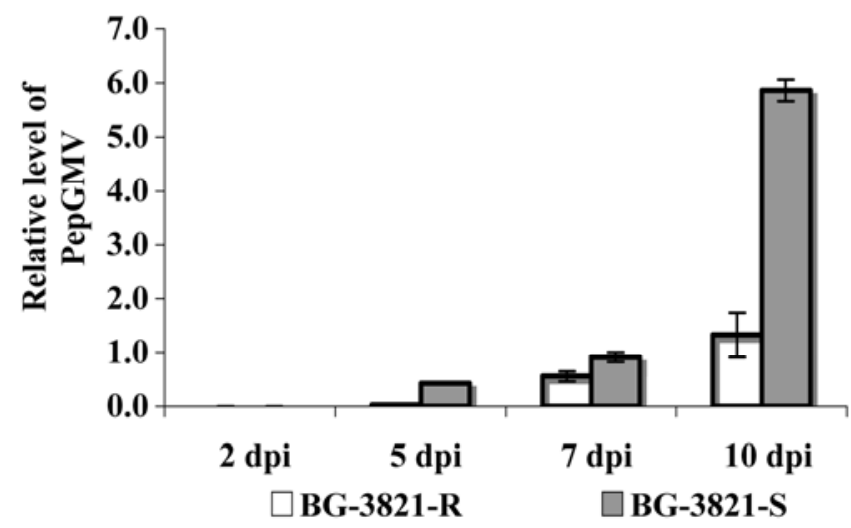

Fig. 2. Relative level of Pepper golden mosaic virus (PepGMV) in systemic leaves. Level of PepGMV was evaluated by quantitative polymerase chain reaction. Primers for Rep gene were used to determine the level of PepGMV replication and primers for 18S RNA plant gene for data normalization; dpi = days postinoculation. hpi using a tissue printing procedure. The analysis showed a strong hybridization signal for PepGMV DNA in the petiole of susceptible plants but not in similar tissue from resistant leaves (Fig. 4A). To confirm these observations, the analysis was also carried out with a more sensitive assay such as PCR. With this procedure, it was possible to detect PepGMV in both resistant and susceptible systemically infected leaves, although the virus concentration in resistant plants was very low (Fig. 2).

Viral movement using modified virus expressing GFP as a reporter has been evaluated in other models. For instance, Bean dwarf mosaic virus (BDMV) fused to GFP (BDMVGFP) was used to evaluate viral movement in resistant and susceptible cultivars of common bean (Garrido-Ramirez et al. 2000; Sudarshana et al. 1998; Wang et al. 1999). Here, viral movement in systemically infected leaves was evaluated using PepGMVA-GFP (Méndez-Lozano et al. 2003). In general, the signal of GFP was confined to small foci located in primary and secondary veins. Evaluations at 6 dpi showed the presence of GFP signal in the first vein of susceptible leaves and, in contrast, a very weak signal was detected in resistant leaves. Significant differences were detected at 12 dpi. In susceptible leaves, it was possible to detect an intense GFP signal in secondary veins. However, in resistant leaves, the weak GFP signal was still restricted to the first vein (Fig. 4B). These results are consistent with the differences in PepGMV accumulation,
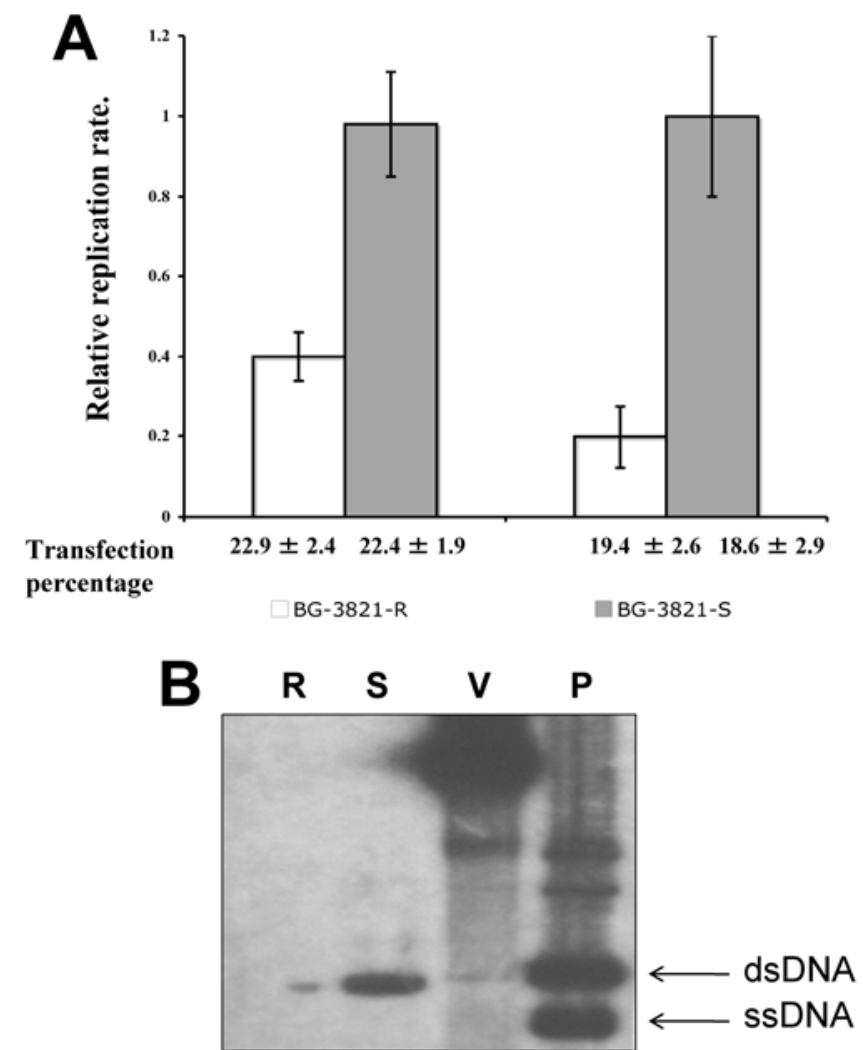

Fig. 3. Pepper golden mosaic virus (PepGMV) replication in protoplasts. Protoplast obtained from leaves of resistant and susceptible plants were transfected with PepGMV-A. A, Viral replication was evaluated $48 \mathrm{~h}$ posttransfection (hpt) by quantitative polymerase chain reaction. Primers for Rep gene were used to determine the level of PepGMV replication and primers for $18 \mathrm{~S}$ plant gene for data normalization. Data from two independent experiments (I and II) are presented. Each experiment includes three independent transfections. Percentage of transfection (estimated using 35S:green fluorescent protein as a reporter) for each experiment. B, Viral replication was evaluated $48 \mathrm{hpt}$ by quantitative Southern blot hybridization. In different samples: protoplast from resistant plants (R), protoplast from susceptible plants (S), plasmid containing PepGMV-A (V), and DNA extract from a PepGMV-infected plant (P). 
A

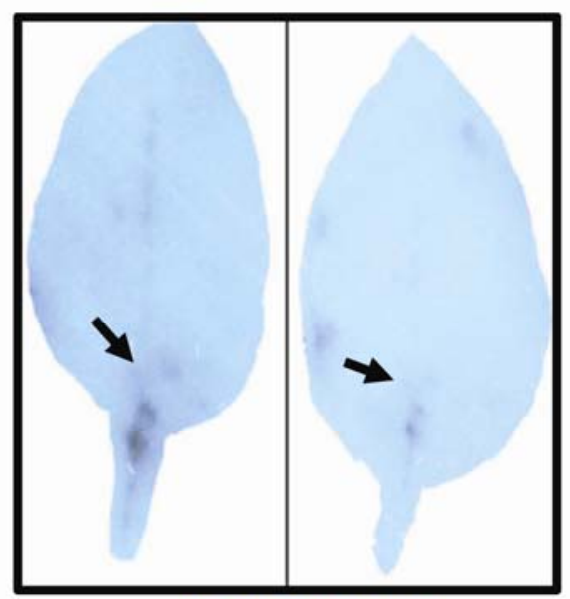

BG-3821-R

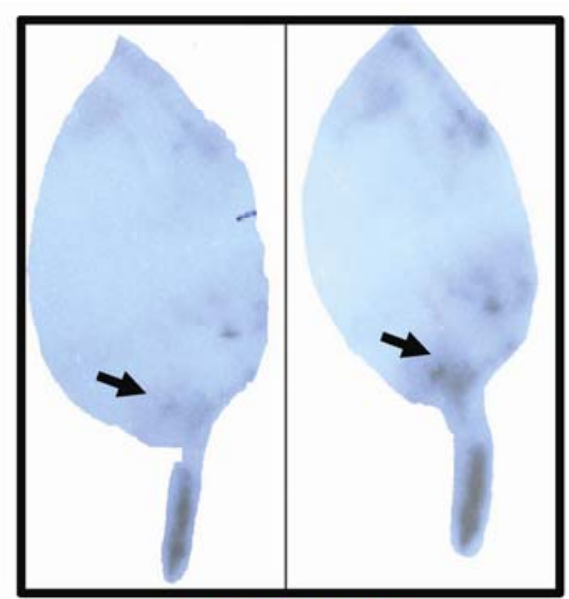

BG-3821-S

B

BG-3821-S

PepGMVA-GFP

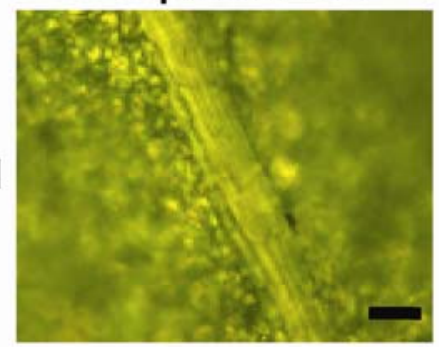

흥

$\omega$

Fluorescence
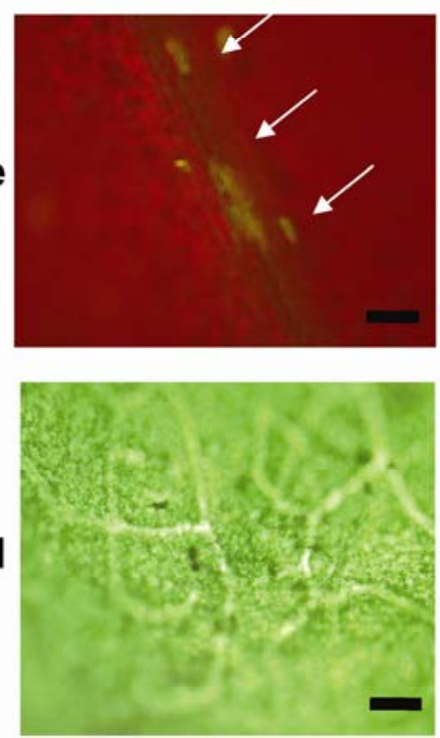

흠
든

Fluorescence

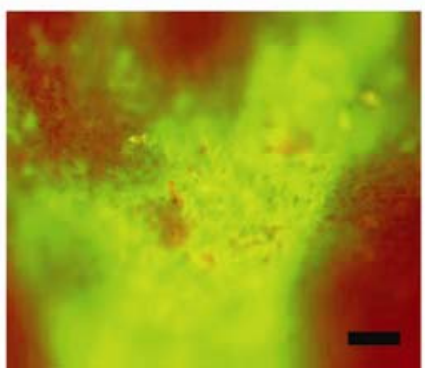

BG-3821-R

PepGMVA-GFP
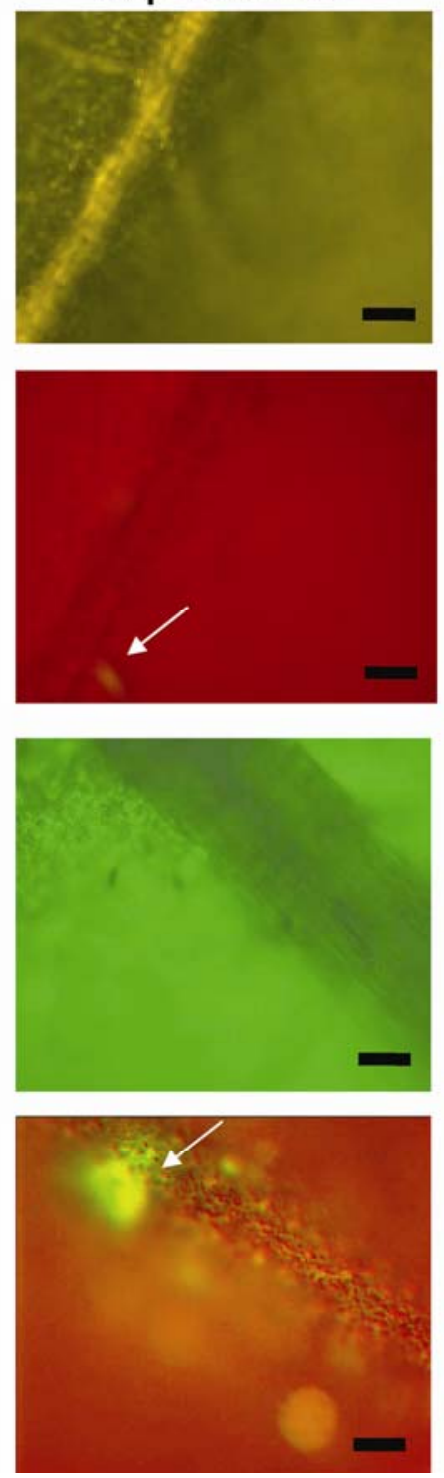

BG-3821-S

Mock
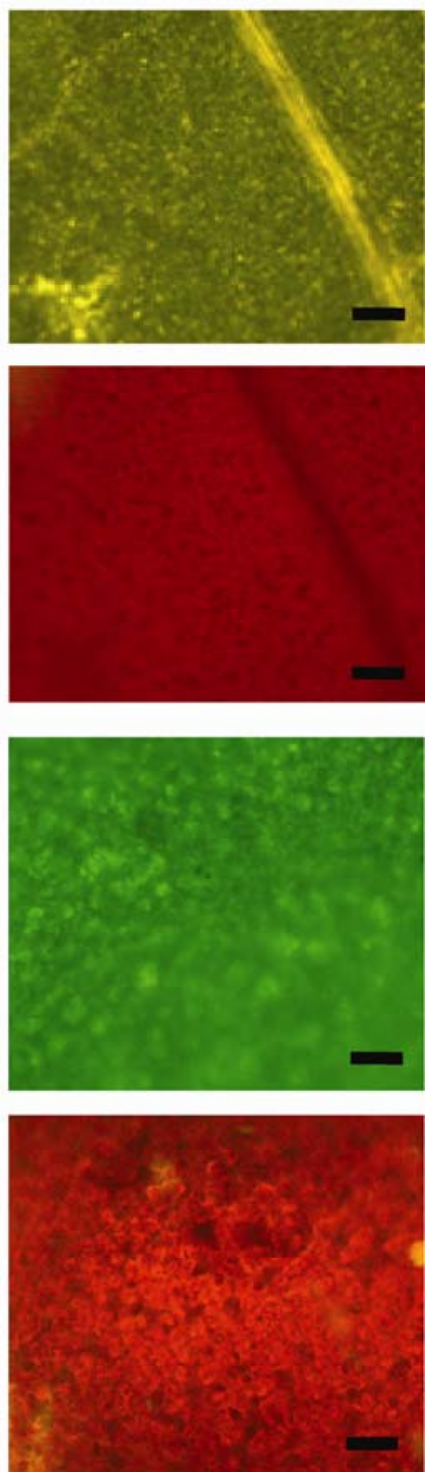

Fig. 4. Evaluation of local and systemic viral movement. A, Viral movement was evaluated by tissue printing $48 \mathrm{~h}$ postinoculation (hpi). Two inoculated leaves of BG-3821-S and BG-3821-R are shown. Inoculation site is indicated by an arrow. B, Systemic movement was evaluated 6 and 12 days postinoculation (dpi) using Pepper golden mosaic virus A (PepGMVA) green fluorescent protein (GFP). Bright-field and fluorescent images of BG-3821-S and BG-3821-R are shown. Presence of GFP is indicated by an arrow. Scale bar $=100 \mathrm{~mm}$. 
detected by quantitative PCR, in systemically infected leaves of resistant and susceptible plants (Fig. 2).

Because the variations observed in movement could still be influenced by the difference in replication, another approach was included. Double scions [(BG-3821-R)-Sonora Anaheim] and [(BG-3821-S)-Sonora Anaheim] were grafted onto a Sonora Anaheim rootstock previously infected with PepGMV (Fig. 5A). In these double grafts, both rootstock and final scion were Sonora Anaheim tissues, which support an efficient viral replication. The objective was to determine whether the resistant intermediate tissue could retard virus movement from the infected rootstock to the susceptible apex. Two independent experiments, including five plants in each case, were carried out. In these experiments, we were able to detect PepGMV by PCR in apical leaves from susceptible grafts 5 days after grafting (dag). At that time, no virus was detected in the apex from the graft including the resistant intermediate scion. Typical symptoms appeared in grafts with a susceptible intermediate scion 13 to 16 dag (Fig. 5B), whereas resistant grafts showed mild symptoms only 21 to $26 \mathrm{dag}$.

\section{SA accumulation is higher}

in resistant plants inoculated with PepGMV.

As a part of the characterization of the resistance to PepGMV in accession BG-3821, we were interested in determining which defensive mechanism could be involved. In plants, SAR is one of the most conserved and important defense mechanisms (Chivasa et al. 1997; Durrant and Dong 2004; Kachroo et al. 2000; Vlot et al. 2009). Moreover, in sev- eral reports, it has been suggested that SAR is involved in some cases of Geminivirus resistance (Garrido-Ramirez et al. 2000; Seo et al. 2004, 2006). Therefore, we decided to SA accumulation, which is a highly conserved hallmark of SAR induction. We evaluated SA accumulation in resistant and susceptible plants after inoculation with PepGMV in both inoculated and systemically infected tissues. The tissues were collected for SA quantification at 2, 5, 7, and 10 dpi. In the case of the inoculated leaves, we detected a two- to threefold increase in SA levels in resistant tissue when compared with similar tissue from a susceptible plant. In both cases, the highest concentration was observed at $5 \mathrm{dpi}$, followed by a dramatic reduction to basal levels at 7 and 10 dpi. In other words, the kinetic of SA production was similar in both resistant and susceptible plants although the concentration on resistant plant was two- to threefold higher. On the systemically infected tissues, however, the differences were more noticeable. In the case of the resistant systemic tissue, a bimodal response (in terms of SA levels) was detected, with a peak as early as 2 dpi and a second peak at $7 \mathrm{dpi}$. In the case of the susceptible tissue, a bimodal response was also observed. However, in this case, the first and smaller peak was obtained at 5 dpi whereas a second, stronger peak was observed at $10 \mathrm{dpi}$. In general, SA accumulation was higher on inoculated leaves when compared with the levels observed in systemically infected ones (Fig. 6A). These results are consistent with previous reports (Durrant and Dong 2004; Vlot et al. 2009). Interestingly, SA accumulation in mock-inoculated or healthy plants remains in a basal state (SA at approximately $80 \mathrm{ng} \mathrm{g}^{-1}$ of fresh-weight tissue).

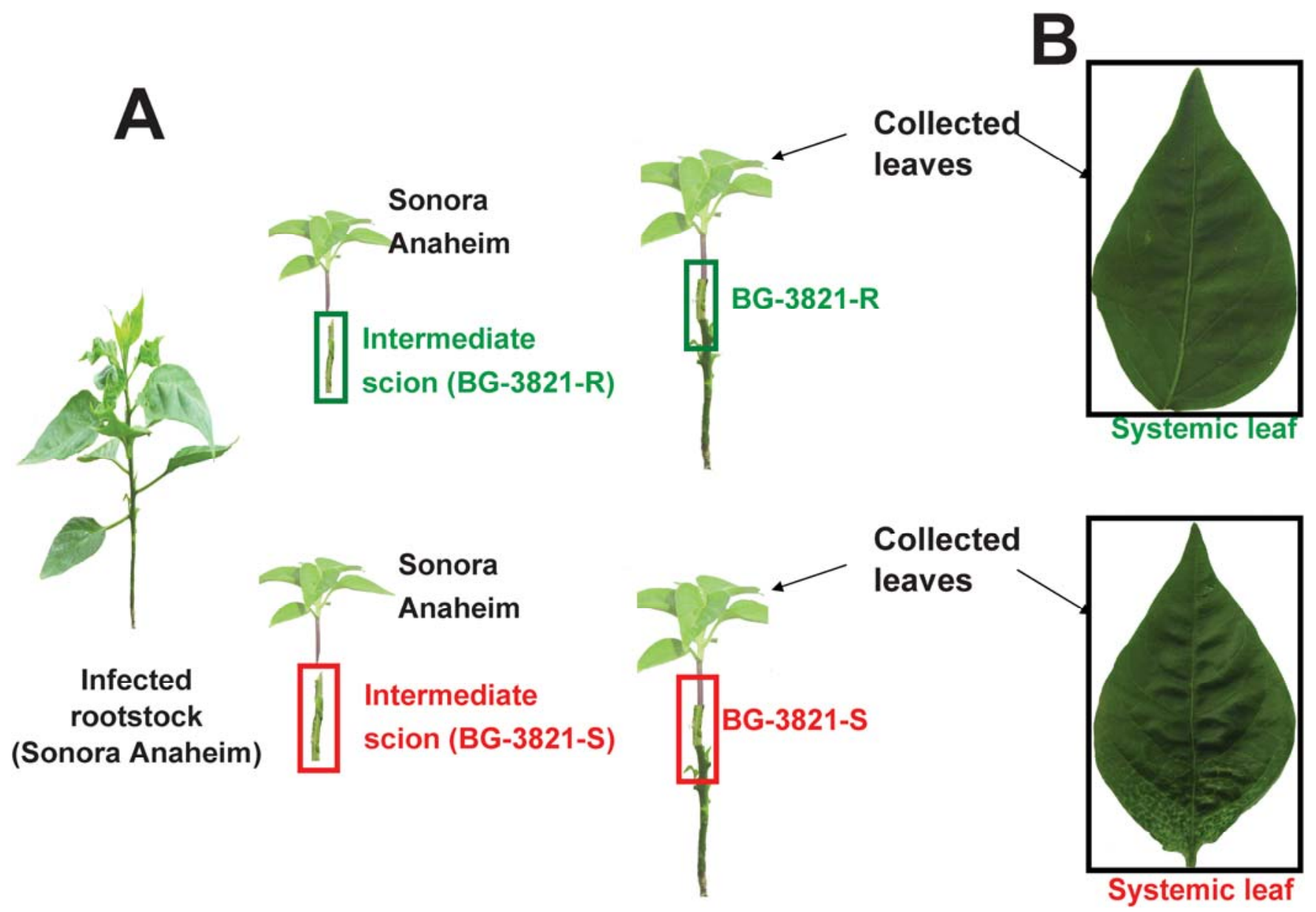

Fig. 5. Double grafting experiments for viral movement evaluation. A, Schema of grafting experiments. Double (BG-3821-R)-Sonora Anaheim or (BG-3821S)-Sonora Anaheim scions were grafted onto a Sonora Anaheim rootstock previously infected with Pepper golden mosaic virus (PepGMV). B, Systemic Sonora Anaheim leaves collected 13 days after grafting. 


\section{Markers of SAR are induced}

in systemically infected leaves of resistant plants.

The expression of PR-1 and PR-5 genes, two markers of SAR, was also evaluated at the same time points used in the evaluation of SA. The expression of PR-1 and PR-5 was undetectable in healthy and mock-inoculated plants at evaluated times of 2, 5, 7, and 10 dpi. In addition, the expression of both genes was also undetectable on the inoculated leaves of both resistant and susceptible plants infected with PepGMV. However, in the case of the systemically infected leaves, a dramatic difference was observed between the resistant and susceptible plants. In the resistant plants, PR-1 expression was detected, increased over time, and peaked at day 7. By $10 \mathrm{dpi}$, the expression of PR-1 was already undetectable. In the case of susceptible plants, no PR-1 expression was observed in all samples analyzed, suggesting that either PR-1 is not induced or its expression in susceptible plants is induced after $10 \mathrm{dpi}$. The fact that susceptible plants infected with Xanthomonas campestris did express the PR-1 gene demonstrates that the PCR detection procedure in susceptible plants is functional. Interestingly, similar results, in terms of PR1 expression, were obtained with Sonora Anaheim plants, also a susceptible cultivar. Another marker for SAR is the expression of PR-5 gene which produce comparable results. The peak of expression of PR-5 was observed at $7 \mathrm{dpi}$ in the case of the resistant plants. However, for the susceptible plants, a PR-5 peak was also observed but at 10 dpi (Fig. 6B). These results suggest that the resistance to Geminivirus infection observed in this $C$. chinense accession is due, at least partially, to a faster and stronger SAR response.

\section{Reactive oxygen production is higher}

on inoculated resistant leaves.

It is generally accepted that there is a positive feedback regulation between reactive oxygen species (ROS) and SAR (Durrant and Dong 2004; Vlot et al. 2009). There is some evidence that ROS production is part of a signaling network for SAR induction. For instance, it has been reported that genes such as manganese superoxide dismutase (MnSOD), catalase (CAT), and peroxidase (POX), which are related to $\mathrm{H}_{2} \mathrm{O}_{2}$ production, are also induced by pathogens and SA, and that these inductions are important for SAR establishment (Bowler et al. 1989; Chen et al. 1993; Conrat et al. 1995; Leon et al. 1995).

ROS are produced in plants as a byproduct of aerobic metabolism. Normally, plants rely on enzymatic and nonenzymatic mechanisms to prevent the increase of ROS concentration, which causes damage to lipids, proteins, and DNA. However, ROS also have a role as signal molecules in pathogen response, and the induction of ROS by different viral pathogens has been reported (Allan et al. 2001; Apel and Hirt 2004; Chen et al. 1993; Conrat et al. 1995; Leon et al. 1995). In common bean, Geminivirus resistance has been associated with the presence of
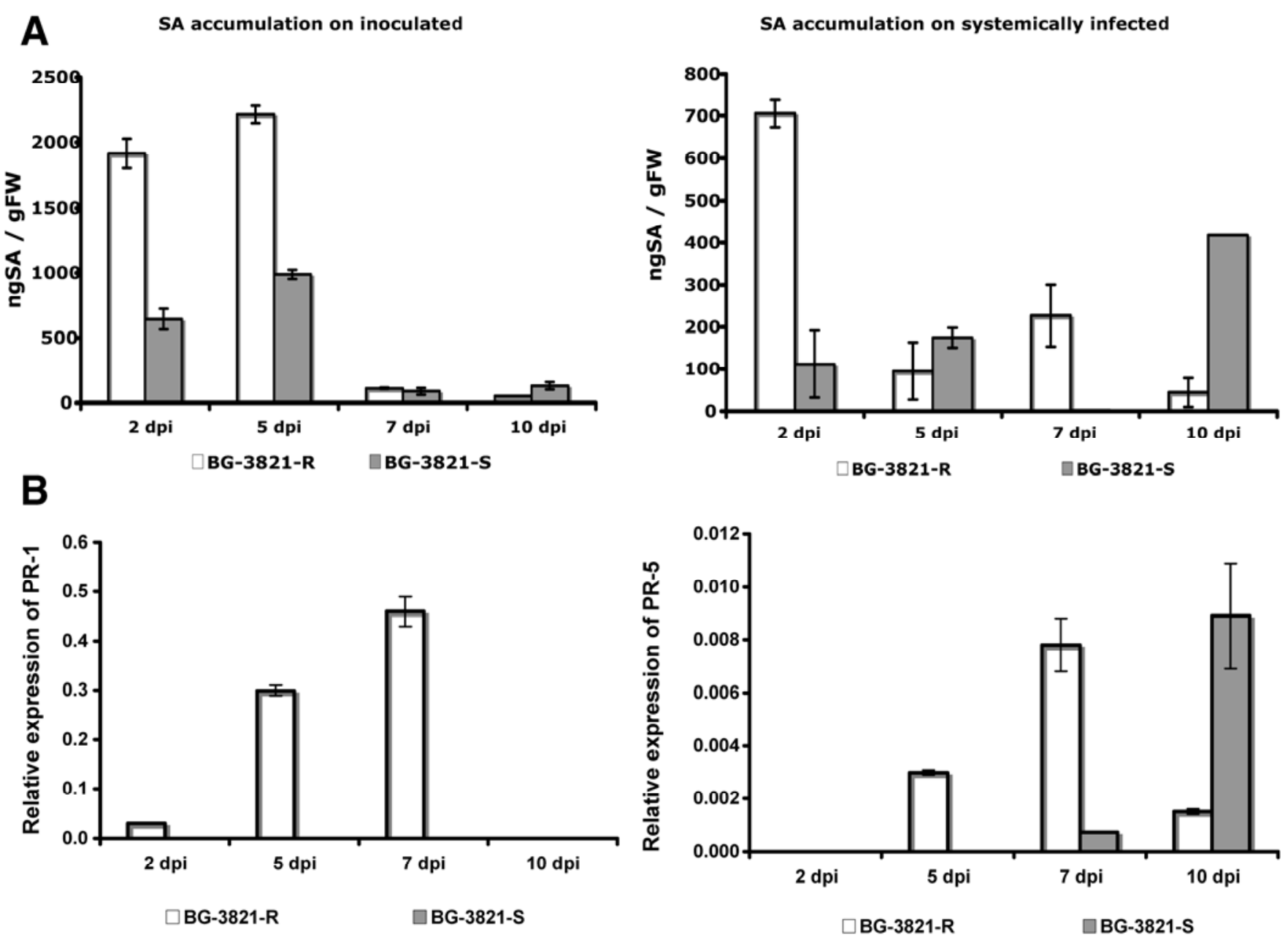

Fig. 6. Accumulation of salicylic acid (SA) and pathogenesis-related (PR) protein expression in resistant and susceptible plants. A, Accumulation of SA on inoculated and systemic leaves of plants infected with Pepper golden mosaic virus (PepGMV). B, Evaluation by quantitative reverse-transcription polymerase chain reaction of PR-1 and PR-5 expression on systemic leaves of PepGMV-inoculated resistant and susceptible plants. Expression of $\beta$-tubulin was used for data normalization; dpi $=$ days postinoculation. 
the hypersensitive response (HR) (Garrido-Ramirez et al. 2000). In pepper, previous work with this $C$. chinense accession (BG3821) using a differential display analysis showed that a germinlike protein with activity of superoxide dismutase is induced after Geminivirus infection (Gasca-González et al. 2008).

To investigate whether ROS production is related to the Geminivirus resistance observed in BG-3821, susceptible and resistant plants were inoculated with PepGMV and analyzed for $\mathrm{H}_{2} \mathrm{O}_{2}$ accumulation using diaminobenzedene (DAB) staining. According to previous reports, induction of $\mathrm{H}_{2} \mathrm{O}_{2}$ by pathogen infection has a biphasic response, with the second peak of $\mathrm{H}_{2} \mathrm{O}_{2}$ production at 6 to $8 \mathrm{hpi}$ (Lamb and Dixon 1997). Our results showed more accumulation of $\mathrm{H}_{2} \mathrm{O}_{2}$ at 6 hpi in PepGMV-inoculated leaves of resistant plants than in similar leaves from susceptible plants. $\mathrm{H}_{2} \mathrm{O}_{2}$ production was also visible in mock-inoculated leaves, although it was confined around the inoculation site (Fig. 7A).

To explain accumulation of $\mathrm{H}_{2} \mathrm{O}_{2}$ in inoculated leaves, the expression of genes related to ROS production was evaluated by quantitative PCR. We chose an MnSOD that had been reported as inducible by stress, SA, and pathogen infection (Bowler et al. 1989). Expression of MnSOD in healthy, noninoculated plants was barely detectable in both susceptible and resistant plants. After bombardment with PepGMV or pBS DNA (virus and mock inoculation, respectively), resistant plants showed three- to fivefold higher expression of the MnSOD gene compared with susceptible plants. Two observa- tions can be made with these results. First, MnSOD expression was induced by mechanical damage caused by the biolistic inoculation because similar levels were observed in both mockand virus-inoculated plants. Second, the induction of MnSOD expression is higher in resistant plants than in susceptible plants (Fig. 7B).

We also evaluated the expression of an iron superoxide dismutase (FeSOD), another enzyme involved in $\mathrm{H}_{2} \mathrm{O}_{2}$ metabolism (Tsang et al. 1991). Infection with PepGMV did not induce FeSOD expression because the values obtained in virus-infected plants were similar to or even lower than those observed in mock-inoculated controls. Healthy control plants from both resistant and susceptible lines showed similar, high basal expression levels (Supplementary Fig. S3).

The third gene evaluated was $C A T$, which codes for the enzyme catalase involved in scavenging of $\mathrm{H}_{2} \mathrm{O}_{2}$ (Chen et al. 1993; Conrat et al. 1995; Yi et al. 2003). Interestingly, CAT expression was induced in both virus- and mock-inoculated susceptible plants, again suggesting a mechanical damage response. In contrast to the other genes tested, in the case of CAT, the resistant plants did not show induction of expression after virus or mock inoculation (Fig. 7B). Plants can also produce $\mathrm{H}_{2} \mathrm{O}_{2}$ using peroxidases and oxidases whose expression can be regulated by biotic and abiotic stimuli (Apel and Hirt 2004). Therefore, we additionally evaluated the expression of POX, which had been reported as inducible by $X$. campestris in pepper (Choi et al. 2007). The pattern of POX induction was simi-

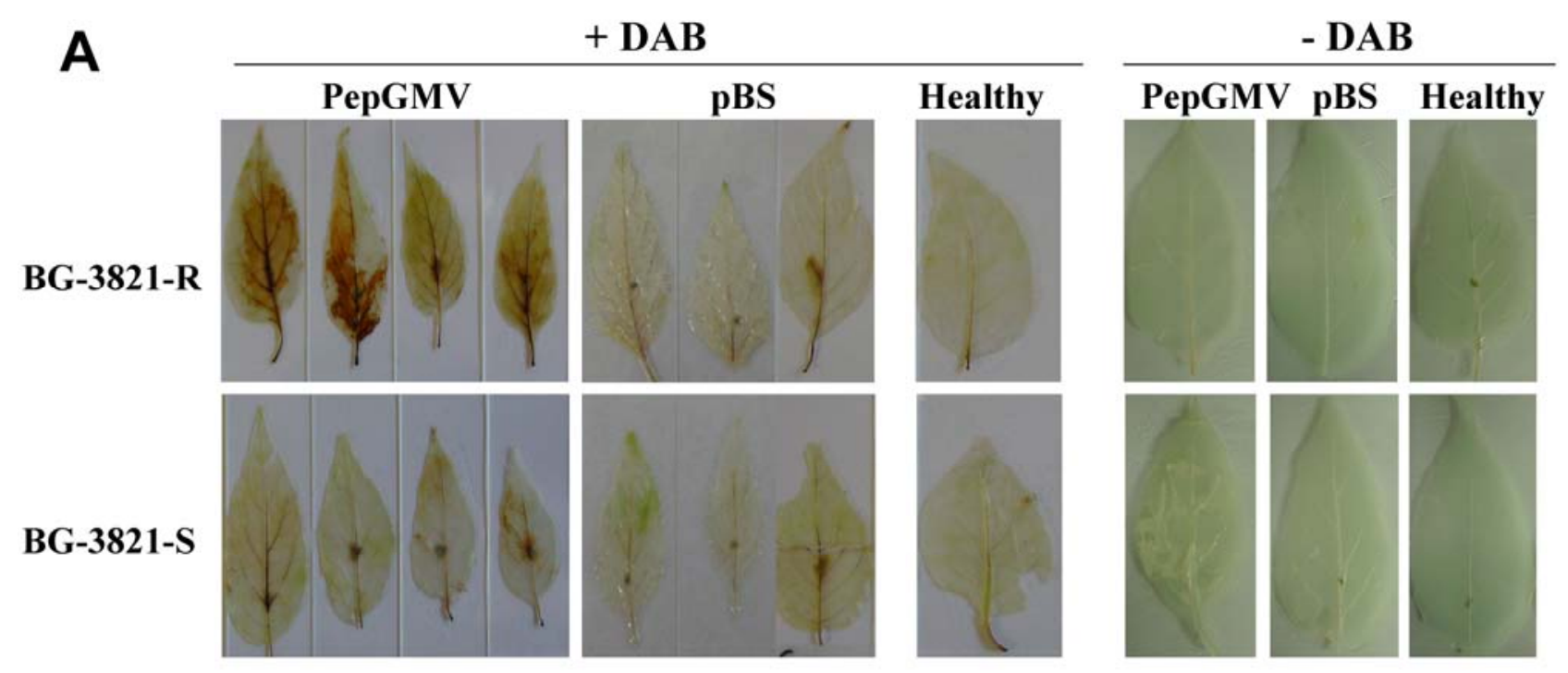

\section{B}
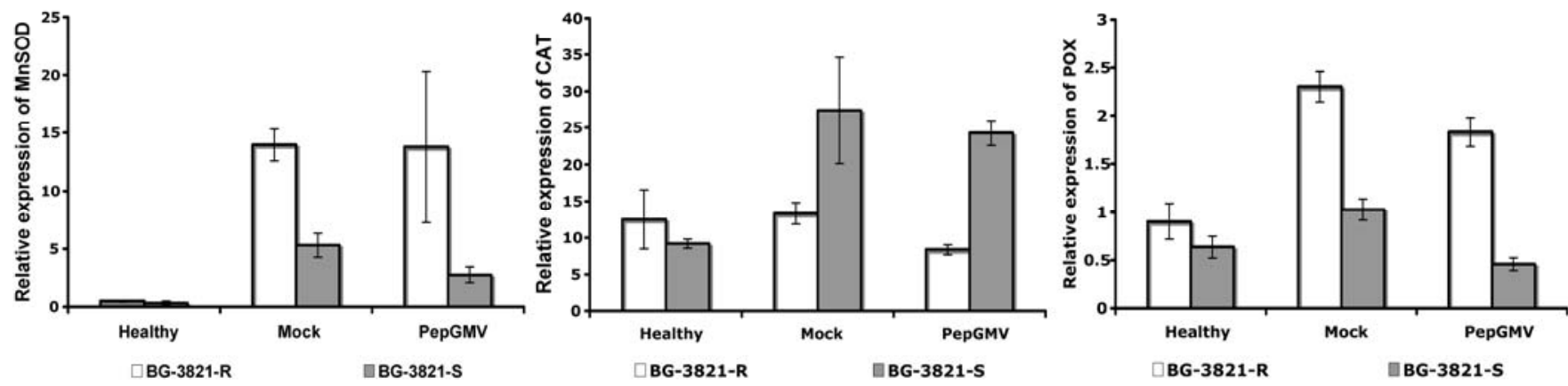

Fig. 7. Evaluation of reactive oxygen species (ROS) production. A, Evaluation of $\mathrm{H}_{2} \mathrm{O}_{2}$ production by diaminobenzedene (DAB) staining. Inoculated resistant and susceptible leaves were evaluated $6 \mathrm{~h}$ postinoculation (hpi). Inoculation site is indicated by an arrow. $\mathbf{B}$, Genes related to $\mathrm{H}_{2} \mathrm{O}_{2}$ production and scavenging were evaluated by quantitative polymerase chain reaction. Expression of $\beta$-tubulin was used for data normalization. Evaluation was done using inoculated leaves 6 hpi. MnSOD = manganese superoxide dismutase, $\mathrm{CAT}=$ catalase, and POX = peroxidase. 
lar to the pattern of MnSOD induction: a higher expression in resistant plants than in susceptible ones, perhaps due to mechanical damage (Fig. 7B).

In summary, under the conditions tested here, it was not possible to determine whether the increased gene expression for MnSOD and POX genes is due only to the mechanical damage of the biolistic inoculation or whether the virus infection contributed somehow. Nevertheless, the results did confirm differences in the stress response between the resistant and susceptible plants. In addition, the fact that the experiment with DAB staining also showed differences between mock- and virusinoculated resistant plants suggests that additional genes, other that the ones tested here, could be involved in the differential $\mathrm{H}_{2} \mathrm{O}_{2}$ production observed in our system, as evidenced with DAB staining.

\section{DISCUSSION}

Geminivirus spp. are major pathogens of several economically important crops. Current methods to control diseases caused by these viruses are often insufficient; therefore, breeding for resistance has always been a major objective for seed producers and breeders (Ji et al. 2007; Lapidot and Friedmann 2002; Shepherd et al. 2009; Vanderschuren et al. 2007). Identification and characterization of useful accessions is a priority for a successful breeding program. Different efforts have been carried out to identify resistance sources in crops such as tomato, cassava, cotton, and bean (Garrido-Ramirez et al. 2000; Ji et al. 2007; Lapidot and Friedmann 2002; Seo et al. 2004; Vidavski et al. 2008; Wang et al. 1999). Pepper accession BG3821, with resistance to PepGMV and PHYVV, has been recently identified (Anaya-López et al. 2003) and, in this work, this resistance trait was further characterized. The results presented here provide information on several aspects of resistance, such as the genetic complexity of the trait, the processes of the viral cycle affected in resistant plants, and pathways probably involved in the resistance mechanism.

The difficulty of introgression of a trait from some accessions (i.e., field-collected wild relatives) into commercial cultivars depends on the genetic complexity of the trait. In an effort to investigate inheritance of the Geminivirus resistance trait in BG-3821, a segregation analysis was carried out. In a previous work, several plants from a field selection experiment were further analyzed in greenhouse assays (Anaya-López et al. 2003). The individual plant BG-3821 again showed good resistance, remaining practically symptomless. Viral DNA concentration was low and only detectable by PCR. To keep its genetic identity, the plant was maintained in the greenhouse and propagated by grafting until a segregation analysis could be performed (this work). Our segregation results showed that BG-3821 was heterozygotic for the Geminivirus resistance trait (Table 1). Crossing C. chinense (resistant) and C. annuum (susceptible) was not an efficient procedure under our conditions; therefore, we decided to evaluate the $\mathrm{S} 1$ progeny as an alternative. Our results suggest that resistance depends on two genes in a duplicate recessive epistatic relation, which means that, in a resistant plant, these two genes should be in their dominant allele (Table 1). Digenic control of Geminivirus resistance has been reported for cotton (Ahuja et al. 2007). In addition, there is also molecular evidence of epistasis between two genes involved in resistance to other pathogens ( $\mathrm{Gu}$ et al. 2000; Kachroo et al. 2000). Another possibility to explain our results is that both alleles have an additive effect and the cumulative effect is necessary to produce resistance. Similarly, there are examples where several genes with additive effect are needed to obtain an effective Geminivirus resistance (Vidavski et al. 2008).
Reports on the characterization of Geminivirus resistance genes are rather scarce. Nevertheless, the variability observed among them suggests many possibilities for defense mechanisms. For example, a TYLCV resistance trait in tomato depends on a recessive allele (Bian et al. 2007), whereas TY-1, an important gene for TYLCV tolerance, has been reported with partial dominance (Zamir et al. 1994). In Phaseolus vulgaris L. cv. Othello, a resistant trait to BDMV depends on one dominant gene (Seo et al. 2004). Digenic control in different epistatic relations such as 13:3, 15:1, and 9:7 has been reported in a resistance trait to Geminivirus diseases in cotton (Ahuja et al. 2007).

Regarding the question of which viral process is affected in the resistant plants, the results presented here indicate that virus replication is less efficient in resistant cells (Fig. 3). The protoplast system allowed us to determine the level of viral replication in resistant cells without the interference of factors involved in movement. Results also suggest that viral movement is also less efficient in resistant plants than in susceptible ones (Figs. 4 and 5). However, a systemic infection process is considered the total sum of replication, movement, host defense, and viral counter-defense reactions (Ueki and Citovsky 2007); therefore, it is almost impossible, at the moment, to isolate the systemic movement itself from the rest of the overall process that includes replication. An initial analysis suggested that long-distance movement is basically not affected. For example, PepGMV detected as viral DNA by PCR or by GFP fluorescence was found in the systemically infected leaves at basically the same time in both resistant and susceptible plants. The main difference found was only in quantitative terms (DNA concentration in PCR assays or the size of the fluorescent cell cluster in GFP assays). This suggests that the virus has similar long movement rates in both types of plants but, once it arrives, it spreads locally in a faster rate on the susceptible plants, perhaps due to higher replication rates. A similar result was recently reported for Plum pox virus (PPV), where it was found that PPV long-distance movement was permitted in a resistant host although virus accumulation was highly reduced (Ion-Nagy et al. 2006). In the double-grafting experiment, plants with a resistant middle scion developed symptoms almost 10 days later than the time required for plants with a susceptible middle scion. A possible explanation is that, for a long-distance movement in this system (pepper-PepGMV), the virus requires a "stop and replicate" mechanism, as suggested in other models with a transgenic, resistant middle scion (ArceJohnson et al. 1997). On the other hand, it is possible that the injury due to the grafting procedure is causing an enhanced defense response like the one observed in the mock inoculation (Fig. 7B).

In other systems, Geminivirus resistance has been associated with less efficient replication (Akad et al. 2007; Brunetti et al. 2001; Czosnek et al. 1993; Day et al. 1991; Lopez-Ochoa et al. 2006; Lucioli et al. 2003) or impaired movement (Bian et al. 2007; Wang et al., 1999), resulting in lower viral concentration in systemically infected tissues. Similarly, a recovery phenotype also has been correlated with a low concentration of PepGMV in recovered leaves (Carrillo-Tripp et al. 2007). Considering that both replication and movement processes are important in viral cycle (Rojas et al. 2005) and both processes seem to be affected in resistant plants (Figs. 3, 4, and 5), the final result is a lower viral concentration in all tissues (Fig. 2) and, as a consequence, the absence of symptoms in resistant plants (Fig. 1).

As a part of the characterization of the resistance trait, we were also interested in the defense mechanisms that could participate in the process. This information could help us to 
determine useful markers to support breeding processes currently in progress. SA is a phenolic compound, which has several implications in plant growth and development, including a key participation as a signal in disease resistance (Durrant and Dong 2004; Vlot et al. 2009). We showed that there is a higher accumulation of SA in resistant leaves when inoculated with PepGMV (Fig. 6A), which is a hallmark of SAR induction. Higher concentrations of SA were found 2 and 5 dpi in resistant leaves inoculated with PepGMV (Fig. 6A). Also, we evaluated the expression of some markers of SAR. We showed that PR-1 and PR-5 are induced 5 and 7 dpi in systemic tissue of resistant plants inoculated with PepGMV (Fig. 6B). The time lag between SA accumulation and PR induction could be explained if we consider that there are several intermediate steps between these two events, including NPR 1 translocation, interaction NPR 1 with TGA transcription factors, and, finally, PR induction. In fact, induction of PR genes is considered a late response to SA accumulation on inoculated leaves (Vlot et al. 2009). Our results suggest the participation of SAR in PepGMV resistance. These results are consistent with previous reports where Geminivirus resistance has been shown to correlate with the induction of resistance gene analogues and SAR (Seo et al. 2006).

There is increasing evidence that SAR and ROS production are closely related (Durrant and Dong 2004; Kachroo et al. 2000; Vlot et al. 2009). For instance, it has been reported that enzymes related to ROS production are induced by SA as well as pathogen attack (Bowler et al. 1989). It has been also shown that catalase activity is inhibited by SA (Chen et al. 1993; Conrat et al. 1995), and the activity and transcription of catalase is also inhibited by $\mathrm{H}_{2} \mathrm{O}_{2}$ ( $\mathrm{Yi}$ et al. 2003). This evidence suggests that ROS level plays a role in the induction of defense responses such as SAR. Using DAB staining, we showed that there is an increase in $\mathrm{H}_{2} \mathrm{O}_{2}$ level in resistant, PepGMV-inoculated leaves (Fig. 7A). This result was correlated with an induction of MnSOD and POX genes related to production of $\mathrm{H}_{2} \mathrm{O}_{2}$. In contrast, CAT, a gene related to $\mathrm{H}_{2} \mathrm{O}_{2}$ scavenging, was induced in inoculated susceptible leaves. These responses appear very early (6 hpi) after PepGMV inoculation; to our knowledge, this is the first evaluation of early responses to Geminivirus infection. Interestingly, the pattern of induction of MnSOD, POX, and CAT was similar in mock- and PepGMV-inoculated leaves (Fig. 7B). Nevertheless, it has been reported that ROS production could be independent of the downstream events related to resistance (Allan et al. 2001; Yi et al. 2003). Indeed, in our system, we did not find SA accumulation or PR induction in mock-inoculated plants.

Taking into account all data discussed here, we propose that PepGMV resistance in BG-3821 depends, at least partially, on an early response to PepGMV inoculation. This early response includes the induction of genes related to $\mathrm{H}_{2} \mathrm{O}_{2}$ production. The increase in $\mathrm{H}_{2} \mathrm{O}_{2}$ level is important to influence the general physiological state of the plant, including SAR induction. At this moment, we do not have enough solid evidence to propose a more specific mechanism that could explain the influence of SAR and PR induction in either viral process, replication or movement. Because SAR is a complex process that includes connections with others defense routes (Durrant and Dong 2004; Vlot et al. 2009), the participation of other defensive mechanism in the resistance phenotype would not be surprising. For example, in soybean, Geminivirus resistance has been correlated with early degradation of viral RNA, probably by a small interfering (si)RNA mechanism (Yadav et al. 2009). In our case, an siRNA preliminary analysis did not provide enough information to support a similar correlation.

\section{MATERIALS AND METHODS}

\section{Plant material and viral clones.}

An original BG-3821 resistant plant was used to obtain a self-pollinated S1 segregating population (Anaya-López et al. 2003). C. annuum var. Sonora Anaheim, a characterized susceptible cultivar (Carrillo-Tripp et al. 2007; Méndez-Lozano et al. 2003), was used as rootstock in grafting experiments and as inoculation control in segregation analysis. PepGMV $(A+B)$ dimeric clones used in this work were previously reported (Carrillo-Tripp et al. 2007) and the PepGMVA-GFP clone has been described (Méndez-Lozano et al. 2003).

\section{Segregation analysis.}

S1 progeny of an original BG-3821 resistant plant was obtained by self pollination. These plants were grafted onto Sonora Anaheim (plants with six to eight true leaves). Segregation analysis was carried out in an insect-free greenhouse.

\section{Plant grafting.}

Plant grafting was used to analyze individuals from S1 generation to maintain "noninoculated copies" (source of scion) of the progeny. The grafts were carried out using Sonora Anaheim susceptible plants as rootstock. Individuals from the $\mathrm{S} 1$ generation (self pollination of BG-3821) were used as scions. Once that graft was confirmed as a successful event, the scions were inoculated by a biolistic procedure as described earlier (Carrillo-Tripp et al. 2007). Because the grafts were carried out before inoculation, no bias between resistant and susceptible plants was expected. Overall, there was a $90 \%$ rate of success in all grafting attempts.

\section{Plant inoculation.}

Plants were inoculated with PepGMV as previously reported (Carrillo-Tripp et al. 2007). Several conditions (DNA concentration, number of inoculated leaves and gun shots, and so on) have been tested for our pepper system. However, symptom severity and time of appearance were not affected in a wide range of viral DNA concentration in the inoculum (I. RenteriaCanett and R. F. Rivera-Bustamante, unpublished results).

\section{Evaluation of PepGMV accumulation in systemically infected leaves.}

DNA extraction was done according to Dellaporta and associates (1983). Relative concentration of PepGMV was evaluated by quantitative PCR as previously reported (CarrilloTripp et al. 2007). Three independent experiments using four plants per experiment were carried out. Two systemically infected leaves were sampled from each plant. A composed sample was evaluated by quantitative PCR. All independent experiments showed the same tendency.

\section{Evaluation of virus replication in protoplasts.}

Protoplast preparation. Virus-free BG-3821-R and BG$3821-S$ plants were used as source material for viral replication evaluation. Protoplasts were obtained using a protocol described by Murphy and Kyle (1994) with some minor modifications. Briefly, i) $5 \mathrm{~g}$ of completely developed young leaves were disinfected with $10 \%$ hypochlorite for $5 \mathrm{~min}$, then were washed twice with $70 \%$ ethanol and, finally, with deionized sterile water; ii) sterile leaves were cut in small pieces and incubated for 10 to $14 \mathrm{~h}$ at $27^{\circ} \mathrm{C}$ in a solution of cellulose $(200$ $\mathrm{mg}$ per $10 \mathrm{ml})$, pectolyase $(20 \mathrm{mg}$ per $10 \mathrm{ml})$, and macerozyme (200 mg per $10 \mathrm{ml}$ ) dissolved in $0.55 \mathrm{M}$ mannitol and $0.1 \% 2$ (N-morpholino) ethanesulfonic acid (MES), pH 5.6; iii) protoplasts solution was filtered using Miracloth (Calbiochem, La Jolla, CA, U.S.A.) for debris elimination; iv) protoplasts were 
collected at $400 \mathrm{rpm}$ in a centrifuge; and v) finally, protoplasts were washed twice in $0.55 \mathrm{M}$ mannitol and 0.1\% MES, pH 5.6.

Protoplast transfection. In brief, $3 \mu \mathrm{g}$ of PepGMV A DNA, cloned in $\mathrm{pBS}$, was used in the transfection. i) Fresh protoplasts $(100,000$ in $200 \mu \mathrm{l})$ were mixed for $20 \mathrm{~s}$ with viral DNA, ii) $100 \mu \mathrm{l}$ of $40 \%$ polyethylene glycol 6000 was added and mixed gently for $30 \mathrm{~s}$, iii) $1 \mathrm{ml}$ of $0.55 \mathrm{M}$ mannitol and $0.1 \%$ MES, pH 5.6, were added and incubated on ice for 15 min, and iv) $8 \mathrm{ml}$ of incubation solution (0.1\% MES, $0.8 \mathrm{mM}$ $\mathrm{KH}_{2} \mathrm{PO}_{4}, 4 \mathrm{mM} \mathrm{KNO}{ }_{3}, 0.4 \mathrm{mM} \mathrm{MgSO} 4,0.4 \mathrm{mM} \mathrm{CaCl}_{2}, 0.02$ $\mathrm{mM} \mathrm{KI}$, and $0.02 \mathrm{mM} \mathrm{CuSO}_{4}$ ) was added and incubated for 48 $\mathrm{h}$ at $27^{\circ} \mathrm{C}$.

Total DNA extraction and evaluation of virus accumulation. Total DNA extraction was done according to Dellaporta and associates (1983). DpnI treatment was carried out as described elsewhere (Lopez-Ochoa et al. 2006). Relative level of PepGMV was evaluated by quantitative PCR and Southern blot as previously reported (Carrillo-Tripp et al. 2007).

\section{Viral movement evaluation.}

Tissue printing. Grafts of BG-3821-R and BG-3821-S were infected with PepGMV $(\mathrm{A}+\mathrm{B})$; at $48 \mathrm{hpi}$, leaves were detached and printed onto a nylon membrane as previously described (Mas and Pallas 1996), then hybridized with a radioactive PepGMV(A) probe as described (Carrillo-Tripp et al. 2007).

GFP analysis. Viral movement in systemically infected leaves was evaluated using a PepGMV-A GFP construction (Méndez-Lozano et al. 2003). Fluorescence was monitored using a Leica DMRE microscope. Images were generated by a digital camera (Spot Diagnostic Instruments) and edited with Adobe Photoshop CS software.

\section{DAB staining.}

Evaluation of $\mathrm{H}_{2} \mathrm{O}_{2}$ production by DAB staining was carried out as previously reported (Orozco-Cardenas and Ryan 1999).

\section{SA quantification.}

SA and SA 2-O- $\beta$-D-glucoside quantification was done using a gas chromatography-mass spectrometry procedure essentially as previously reported (Malamy et al. 1992). SA accumulation was evaluated in duplicate extractions from composed samples. Each composed sample contained two leaves per plant of a total of eight plants from two independent experiments.

\section{Evaluation of gene expression \\ by quantitative reverse-transcription PCR.}

Total RNA extraction was done using TriZOL (Invitrogen, Carlsbad, CA, U.S.A.). DNA contamination was discarded by PCR. One microgram of DNA-free RNA was used for synthesis of cDNA using Superscript II reverse transcriptase (Invitrogen). Quantitative reverse-transcription PCR was done as previously described (Carrillo-Tripp et al. 2007). The following PCR primers were used in this study: $\beta$-tub sense TCCAGTGTTCTGTG ACATCCCGCCTAG, $\beta$-tub antisense CTCCATTTCGTCCAT TCCTTCACCTGTG; PR-1 sense CCCAAAATTACGCCAAT CAAAG, PR-1 antisense ACATCTTCACGGCACCAG; PR-5 sense TGGTGGAGTCTTGCAGTGC, PR-5 antisense CGTGC AATGGATCGCGTG; MnSOD sense CTTTGACGCGATACA GAGGACAT, MnSOD antisense TGCAAATCATACAAACA GGACCAT; CAT sense AAGTATCGCCCATCAAGTGC, CAT antisense AACAGGCCCTCTAGGTCCAACAGT; POX sense GCATCCCTCATTCGCCTTCA, POX antisense GCAATGCC GTTTTCTCACTG, and FeSOD sense ACGCTGCACAGGT TTGGAATC, FeSOD antisense AGCCGAAGTCTCTGTTGA.

Steady expression of $\beta$-tubulin was corroborated by analyzing data of transcriptome of pepper under three different conditions:
Healthy, PepGMV-infected, and PepGMV-recovered leaves (E. Gongora-Castillo and R. F. Revera-Bustamante, unpublished data).

\section{ACKNOWLEDGMENTS}

We thank J. Carrillo-Tripp for critical reading of the manuscript and helpful suggestions, and I. Torres-Pacheco for the accession BG-3821 of Capsicum chinense Jacq., and Conacyt-México for support to M. A. GarcíaNeria (Ph.D. fellowship) and R. F. Rivera-Bustamante (Grant ConacytSAGARPA-2004-115).

\section{LITERATURE CITED}

Ahuja, S. L., Monga, D., and Dhayal, L. S. 2007. Genetics of resistance to cotton leaf curl disease in Gossypium hirsutum L. under field conditions. J. Hered. 98:79-83.

Akad, F., Eybishtz, A., Edelbaum, D., Gorovits, R., Dar-Issa, O., Iraki, N., and Czosnek, H. 2007. Making a friend from a foe: Expressing a GroEL gene from the whitefly Bemisia tabaci in the phloem of tomato plants confers resistance to Tomato yellow leaf curl virus. Arch. Virol. 152:1323-1339.

Allan, A. C., Lapidot, M., Culver, J. N., and Fluhr, R. 2001. An early Tobacco mosaic virus-induced oxidative burst in tobacco indicates extracellular perception of the virus coat protein. Plant Physiol. 126:97108.

Anaya-López, J. L., Torres-Pacheco, I., González-Chavira, M., GarzónTiznado, J. A., Pons-Hernández, J. L., Guevara-González, R. G., MuñozSánchez, C. I., Guevara-Olvera, L., Rivera-Bustamante, R. F., and Hernández-Verdugo, S. 2003. Resistance to geminivirus mixed infections in Mexican wild peppers. HortScience 38:251-255.

Apel, K., and Hirt, H. 2004. Reactive oxygen species: Metabolism, oxidative stress, and signal transduction. Annu. Rev. Plant Biol. 55:373-399.

Arce-Johnson, P., Reimann-Philipp, U., Hall, P., Rivera-Bustamante, R., and Beachy, R. N. 1997. Requirement of the movement protein for the long distance spread of tobacco mosaic virus. Mol. Plant-Microbe Interact. 18:691-699.

Bian, X. Y., Thomas, M. R., Rasheed, M. S., Saeed, M., Hanson, P., De Barro, P. J., and Rezaian, M. A. 2007. A recessive allele (tgr-1) conditioning tomato resistance to geminivirus infection is associated with impaired viral movement. Phytopathology 97:930-937.

Bowler, C., Alliotte, T., De Loose, M., Van Montagu, M., and Inze, D. 1989. The induction of manganese superoxide dismutase in response to stress in Nicotiana plumbaginifolia. EMBO (Eur. Mol. Biol. Organ.) J. 8:31-38.

Brunetti, A., Tavazza, R., Noris, E., Lucioli, A., Accotto, G. P., and Tavazza, M. 2001. Transgenically expressed T-Rep of Tomato yellow leaf curl Sardinia virus acts as a trans-dominant-negative mutant, inhibiting viral transcription and replication. J. Virol. 75:10573-10581.

Carrillo-Tripp, J., Lozoya-Gloria, E., and Rivera-Bustamante, R. F. 2007. Symptom remission and specific resistance of pepper plants after infection by Pepper golden mosaic virus. Phytopathology 97:51-57.

Chen, Z., Silva, H., and Klessig, D. F. 1993. Active Oxygen in the induction of systemic acquired resistance. Science 262:1883-1886.

Chivasa, S., Murphy, A. M., Naylor, M., and Carr, J. P. 1997. Salicylic acid interferes with Tobacco mosaic virus replication via a novel salicylhydroxamic acid-sensitive mechanism. Plant Cell 5:547-557.

Choi, H. W., Kim, Y. J., Lee, S. C., Hong, J. K., and Hwang, B. K. 2007. Hydrogen peroxide generation by the pepper extracellular peroxidase CaPO2 activates local and systemic cell death and defense response to bacterial pathogens. Plant Physiol. 145:890-904.

Conrat, U., Chen, Z., Ricigliano, J., and Klessig, D. F. 1995. Two inducers of plant defense responses, 2,6-dichloroisonicotinic acid and salicylic acid, inhibits catalase activity in tobacco. Proc. Natl. Acad. Sci. U.S.A. 92:7143-7147.

Czosnek, H., Kheyr-Pour, A., Gronenborn, B., Remetz, E., Zeidan, M. Altman, A., Rabinowitch, H. D., Vidavsky, S., Kedar, N., Gafni, Y., and Zamir, D. 1993. Replication of Tomato yellow leaf curl virus (TYLCV) DNA in agroinoculated leaf discs from selected tomato genotypes. Plant Mol. Biol. 22:995-1005.

Day, A. G., Bejarano, E. R., Buck, K. W., Burrell, M., and Lichtenstein, C. P. 1991. Expression of an antisense viral gene in transgenic tobacco confers resistance to the DNA virus Tomato golden mosaic virus. Proc. Natl. Acad. Sci. U.S.A. 88:6721-6725.

Dellaporta, S. L., Woods, J., and Hicks, J. B. 1983. A plant minipreparation, Version II. Plant Mol. Biol. Rep. 1:19-21.

Durrant, W. E., and Dong, X. 2004. Systemic acquired resistance. Annu. Rev. Phytopathol. 42:185-209. 
Garrido-Ramirez, E. R., Sudarshana, M. R., Lucas, W. J., and Gilbertson, R. L. 2000. Bean dwarf mosaic virus BV1 protein is a determinant of the hypersensitive response and avirulence in Phaseolus vulgaris. Mol. Plant-Microbe Interact. 13:1184-1194.

Gasca-González, M. R., Rivera-Herrera, Y., Torres-Pacheco, I., GonzálezChavira, M. M., Guevara-Olvera, L., Muñoz-Sanchez, C. L., and Guevara-González, R. G. 2008. Study on the transcriptome in Capsicum chinense Jacq. resistant to Pepper huasteco yellow vein virus (PHYVV). Agrociencia 42:107-117.

Godínez-Hernández, Y., Anaya-Lopez, J. L., Diaz-Plaza, R., GonzálezChavira, M., Torres-Pacheco, I., Rivera-Bustamante, R. F., and Guevara-González, R. G. 2001. Characterization of resistance to pepper huasteco geminivirus in chili peppers from Yucatan, Mexico. HortScience 36:139-142.

Gu, Y. Q., Yang, C., Thara, V. K., and Martin, G. B. 2000. Pti4 is induced by ethylene and salicylic acid, and its product is phosphorylated by the Pto kinase. Plant Cell 12:771-786.

Hernández-Verdugo, S., Guevara-González, R. G., Rivera-Bustamante, R. F., and Oyama, K. 2001. Screening wild plants of Capsicum annuum for resistance to Pepper huasteco virus (PHV): Presence of viral DNA and differentiation among populations. Euphytica 122:31-36.

Holguín-Peña, R. J., Rivera-Bustamante, R. F., and Carrillo-Tripp, J. 2007. Pepper golden mosaic virus and related geminiviruses affecting tomato crops. In: Characterization, Diagnosis and Management of Plant Viruses. Vol. 3: Vegetable and Pulse Crops. G. P. Rao, P. L. Kumar, and R. J. Holguin-Peña, eds. Studium Press LLC, Houston, TX, U.S.A.

Ion-Nagy, L., Lansac, M., Eyquard, J. P., Salvador, B., Garcia, J. A., Le Gall, O., Hernould, M., Schurdi-Levraud, V., and Decroocq, V. 2006. PPV long-distance movement is occasionally permitted in resistant apricot hosts. Virus Res. 120:70-78.

Ji, Y., Scott, J., Hanson, P., Graham, E., and Maxwell, D. 2007. Sources of resistance, inheritance, and location of genetic loci conferring resistance to members of the tomato-infecting begomoviruses. In: Tomato yellow leaf curl virus Disease. Springer, Dordrecht, The Netherlands.

Kachroo, P., Yoshioka, K., Shah, J., Dooner, K., and Klessig, D. F. 2000. Resistance to Turnip crinkle virus in Arabidopsis is regulated by two host genes and is salicylic acid dependent but NPR1, ethylene, and jasmonate independent. Plant Cell 12:677-690.

Lamb, C., and Dixon, R. A. 1997. The oxidative burst in plant disease resistance. Annu. Rev. Plant Physiol. Plant Mol. Biol. 48:251-275.

Lapidot, M., and Friedmann, M. 2002. Breeding for resistance to whiteflytransmitted geminiviruses. Ann. Appl. Biol. 140:109-127.

Leon, J., Lawton, M. A., and Raskin, I. 1995 Hydrogen peroxide stimulates salicylic acid biosynthesis in tobacco. Plant Physiol. 108:16731678 .

Lopez-Ochoa, L., Ramirez-Prado, J., and Hanley-Bowdoin, L. 2006. Peptide aptamers that bind to a geminivirus replication protein interfere with viral replication in plant cells. J. Virol. 80:5841-5853.

Lucioli, A., Noris, E., Brunetti, A., Tavazza, R., Ruzza, V., Castillo, A. G., Bejarano, E. R., Accotto, G. P., and Tavazza, M. 2003. Tomato yellow leaf curl Sardinia virus Rep-derived resistance to homologous and heterologous geminiviruses occurs by different mechanisms and is overcome if virus-mediated transgene silencing is activated. J. Virol 77:6785-6798.

Malamy, J., Hennig, J., and Klessig, D. F. 1992. Temperature-dependent induction of salicylic acid and its conjugates during the resistance response to tobacco mosaic virus infection. Plant Cell 4:359-366.

Mas, P., and Pallas, V. 1996. Long-distance movement of cherry leaf roll virus in infected tobacco plants. J. Gen. Virol. 77:531-540.

Méndez-Lozano, J., Torres-Pacheco, I., Fauquet, C. M., and RiveraBustamante, R. F. 2003. Interactions between geminiviruses in a naturally occurring mixture: Pepper huasteco virus and Pepper golden mosaic virus. Phytopathology 93:270-277.

Moffat, A. S. 1999. Plant pathology_geminiviruses emerge as serious crop threat. Science 286:1835-1835.
Morales, F. J., and Anderson, P. K. 2001. The emergence and dissemination of whitefly-transmitted geminiviruses in Latin America. Arch. Virol. 146:415-441.

Murphy, J. F., and Kyle, M. M. 1994. Isolation and viral infection of Capsicum leaf protoplasts. Plant Cell Rep. 13:397-400.

Orozco-Cardenas, M., and Ryan, C. A. 1999. Hydrogen peroxide is generated systemically in plant leaves by wounding and systemin via the octadecanoid pathway. Proc. Natl. Acad. Sci. U.S.A. 96:6553-6557.

Rojas, M. R., Hagen, C., Lucas, W. J., and Gilbertson, R. L. 2005. Exploiting chinks in the plant's armor: Evolution and emergence of geminiviruses. Annu. Rev. Phytopathol. 43:361-394.

Seo, Y. S., Gepts, P., and Gilbertson, R. L. 2004. Genetics of resistance to the geminivirus, Bean dwarf mosaic virus, and the role of the hypersensitive response in common bean. Theor. Appl. Genet. 108:786-793.

Seo, Y. S., Rojas, M. R., Lee, J. Y., Lee, S. W., Jeon, J. S., Ronald, P., Lucas, W. J., and Gilbertson, R. L. 2006. A viral resistance gene from common bean functions across plant families and is up-regulated in a non-virus-specific manner. Proc. Natl. Acad. Sci. U.S.A. 103:1185611861.

Shepherd, D. N., Martin, D. P., and Thomson, J. A. 2009. Transgenic strategies for developing crops resistant to geminiviruses. Plant Sci. 176:1-11.

Sudarshana, M. R., Wang, H. L., Lucas, W. J., and Gilbertson, R. L. 1998 Dynamics of bean dwarf mosaic geminivirus cell-to-cell and long-distance movement in Phaseolus vulgaris revealed, using the green fluorescent protein. Mol. Plant-Microbe Interact. 11:277-291.

Torres-Pacheco, I., Garzon-Tiznado, J. A., Brown, J. K., Becerra-Flora, A., and Rivera-Bustamante, R. F. 1996. Detection and distribution of geminiviruses in Mexico and the southern United States. Phytopathology 86:1186-1192.

Tsang, E., Bowler, C., Herouart, D., Van Camp, W., Villarroel, R., Genetello, C., Van Montagu, M., and Inze, D. 1991. Differential regulation of superoxide dismutases in plants exposed to environmental stress. Plant Cell 3:783-792.

Ueki, S., and Citovsky, V. 2007. Spread throughout the plant: Systemic transport of viruses. In: Viral Transport in Plants. E. Waigmann and M. Heinlein, eds. Springer, Berlin.

Vanderschuren, H., Stupak, M., Futterer, J., Gruissem, W., and Zhang, P. 2007. Engineering resistance to geminiviruses-Review and perspectives. Plant Biotechnol. J. 5:207-220.

Varma, A., and Malathi, V. G. 2003. Emerging geminivirus problems: A serious threat to crop production. Ann. Appl. Biol. 142:145-164.

Vidavski, F., Czosnek, H., Gazit, S., Levy, D., and Lapidot, M. 2008. Pyramiding of genes conferring resistance to Tomato yellow leaf curl virus from different wild tomato species. Plant Breed. 127:625-631.

Vlot, A. C., Dempsey, D. A., and Klessig, D. F. 2009. Salicylic acid, a multifaceted hormone to combat disease. Annu. Rev. Phytopathol. 47:177-206.

Wang, H. L., Sudarshana, M. R., Gilbertson, R. L., and Lucas, W. J. 1999. Analysis of cell-to-cell and long-distance movement of a bean dwarf mosaic geminivirus-green fluorescent protein reporter in host and nonhost species: Identification of sites of resistance. Mol. Plant-Microbe Interact. 12:345-355.

Yadav, R. K., Shukla, R. K., and Chattopadhyay, D. 2009. Soybean cultivar resistant to Mungbean yellow mosaic India virus infection induces viral RNA degradation earlier than the susceptible cultivar. Virus Res. 144:89-95.

Yi, S. Y., Yu, S. H., and Choi, D. 2003. Involvement of hydrogen peroxide in repression of catalase in TMV-infected resistant tobacco. Mol. Cells 15:364-369.

Zamir, D., Ekstein-Michelson, I., Zakay, Y., Navot, N., Zeiban, M., Sarfatti, M., Eshed, Y., Harel, E., Pleban, T., Van-Oss, H., Kedar, N., Rabinowitch, H. D., and Czosnek, H. 1994. Mapping and introgression of a tomato yellow leaf curl virus tolerance gene, TY-1. Theor. Appl. Genet. 88:141146. 